\title{
Agricultura de Precisão: monitoramento tecnológico a partir da análise de patentes
}

\author{
Precision Agriculture: technological monitoring based on patent analysis \\ Agricultura de Precisión: seguimiento tecnológico basado en análisis de patentes
}

Recebido: 17/02/2022 | Revisado: 18/02/2022 | Aceito: 20/02/2022 | Publicado: 02/03/2022

\author{
Wanderson de Vasconcelos Rodrigues da Silva \\ ORCID: https://orcid.org/0000-0002-7631-9830 \\ Instituto Federal de Educação, Ciência e Tecnologia do Piauí, Brasil \\ E-mail: wanderson.vasconcelos@ifpi.edu.br \\ Renata Silva-Mann \\ ORCID: https://orcid.org/0000-0001-5993-3161 \\ Universidade Federal de Sergipe, Brasil \\ E-mail: renatamann@academico.ufs.br
}

\begin{abstract}
Resumo
Os sistemas de Agricultura de Precisão adotam diversos equipamentos de alta tecnologia em hardware, software e comunicação para coletar dados de diferentes fontes a fim de medir e avaliar todos os aspectos da produção agrícola. Essa estratégia de gestão permite a racionalização no uso dos recursos agrícolas, aumentando a eficiência da produção ao tempo que reduz os impactos negativos da atividade no campo. Este estudo teve por objetivo realizar o monitoramento das tecnologias associadas à Agricultura de Precisão, a partir da análise de informações dos documentos de patentes, de modo a investigar o estado e as tendências, bem como identificar os principais provedores e suas redes de colaboração. Questões de pesquisa foram formuladas para guiar o estudo, sendo este de caráter tanto quantitativo e descritivo, quanto qualitativo e exploratório. O estudo também fornece um fluxo metodológico apoiado por ferramentas de softwares gratuitos para coleta, tratamento e visualização de dados. Entre os principais resultados, destacam-se: 312 famílias de patentes depositadas por 303 requerentes e 968 inventores foram identificadas; $86 \%$ das publicações de patentes ocorreram na última década com tendência ao crescimento; as tecnologias foram depositadas em 23 países, com destaque para China e Estados Unidos; cerca de 86\% dos titulares e inventores possuem apenas uma patente; plantio, processamento de dados e análise de propriedades do solo são os setores tecnológicos mais desenvolvidos; patentes altamente citadas; principais inventores participam de forma mais cooperativa que os titulares, sendo pontes entre diferentes grupos de inventores.
\end{abstract}

Palavras-chave: Agricultura inteligente; Mapeamento tecnológico; Análise patentométrica; Indicadores.

\begin{abstract}
Precision Farming systems adopt various high-tech equipment in hardware, software and communication to collect data from different sources in order to measure and evaluate all aspects of agricultural production. This management strategy allows the rationalization in the use of agricultural resources, increasing production efficiency while reducing the negative impacts of the activity in the field. This study aimed to monitor the technologies associated with Precision Farming, from the analysis of information from patent documents, in order to investigate the status and trends, as well as to identify the main providers and their collaboration networks. Research questions were formulated to guide the study, and this study is both quantitative and descriptive, and qualitative and exploratory in nature. The study also provides a methodological flow supported by free software tools for data collection, processing and visualization. Among the main results, the following stand out: 312 patent families filed by 303 applicants and 968 inventors were identified; $86 \%$ of the patent publications occurred in the last decade with an increasing trend; technologies were filed in 23 countries, with China and the United States standing out; about $86 \%$ of the holders and inventors own only one patent; planting, data processing and soil property analysis are the most developed technological sectors; highly cited patents; main inventors participate in a more cooperative way than the holders, being bridges between different groups of inventors.
\end{abstract}

Keywords: Smart agriculture; Technological mapping; Patentometric analysis; Indicators.

\section{Resumen}

Los sistemas de agricultura de precisión adoptan varios equipos de alta tecnología en hardware, software y comunicación para recopilar datos de diferentes fuentes con el fin de medir y evaluar todos los aspectos de la producción agrícola. Esta estrategia de manejo permite la racionalización en el uso de los recursos agrícolas, aumentando la eficiencia productiva y reduciendo los impactos negativos de la actividad en el campo. Este estudio tuvo como objetivo monitorear las tecnologías asociadas a la Agricultura de Precisión, a partir del análisis de la información de los documentos de patentes, con el fin de investigar el estado y las tendencias, así como identificar los principales proveedores y sus redes de colaboración. Se formularon preguntas de investigación para guiar el estudio, y 
este estudio es de naturaleza tanto cuantitativa y descriptiva como cualitativa y exploratoria. El estudio también proporciona un flujo metodológico apoyado en herramientas de software libre para la recolección, procesamiento y visualización de datos. Entre los principales resultados destacan: se identificaron 312 familias de patentes presentadas por 303 solicitantes y 968 inventores; El 86\% de las publicaciones de patentes se dieron en la última década con una tendencia creciente; se presentaron tecnologías en 23 países, destacándose China y Estados Unidos; alrededor del 86\% de los titulares e inventores poseen una sola patente; la siembra, el procesamiento de datos y el análisis de las propiedades del suelo son los sectores tecnológicos más desarrollados; patentes muy citadas; los inventores principales participan de manera más cooperativa que los titulares, siendo puentes entre diferentes grupos de inventores.

Palabras clave: Agricultura inteligente; Mapeo tecnológico; Análisis patentométrico; Indicadores.

\section{Introdução}

A sustentabilidade agrícola e a segurança alimentar têm sido temas preocupantes em diversas partes do mundo, uma vez que o solo e a água não são mais recursos inesgotáveis, o que exige maior eficiência na produção. Para garantir a manutenção desses sistemas agrícolas e a produtividade no longo prazo, diversas técnicas de mecanização, irrigação, fertilização, entre outras, foram introduzidas na agricultura ao longo do tempo. Com o uso das Tecnologias da Informação (TI) e, mais recentemente, da Internet das Coisas (IoT) e da Inteligência Artificial (IA), os sistemas de Agricultura de Precisão (AP) têm promovido a otimização do uso de insumos, como sementes, água, fertilizantes, corretivos, defensivos, etc., considerando o mapeamento da variabilidade espacial e temporal dos campos agrícolas (Cisternas et al., 2020; Silva \& Silva-Mann, 2021).

A Agricultura de Precisão é uma estratégia de gestão que utiliza equipamentos de alta tecnologia (hardwares e softwares especializados), criando um sistema complexo que coleta dados de fontes distintas para monitoramento e avaliação de todos os aspectos da produção agrícola. Esses dados fornecem o suporte necessário para a aplicação diferenciada e precisa dos recursos, de modo a aumentar a eficiência, melhorar o rendimento econômico e reduzir o impacto ambiental (Kent Shannon et al., 2018; Silva \& Silva-Mann, 2020).

Relatos sobre o uso de técnicas de precisão na agricultura surgiram desde 1929, mas foi a partir da década de 80 que a filosofia da Agricultura de Precisão (AP) passou a se consolidar, especialmente com o desenvolvimento de sensores e microcomputadores. Na década de 90 , a operacionalização dos sistemas de navegação global trouxe mais avanços significativos na agricultura que passou a fazer uso de Sistemas de Informação Geográfica (SIG) e tecnologias de aplicações diferenciadas, denominadas Variable Rate Technology (VRT). Com isso, a AP permitiu o mapeamento da variabilidade da lavoura, bem como o monitoramento instantâneo da produção (Adamchuk et al., 2004; Precision Agriculture in the 21st Century, 1997)

O objetivo desta pesquisa foi realizar o monitoramento das tecnologias associadas à Agricultura de Precisão, a partir da análise de informações dos documentos de patentes publicados, de modo a investigar o atual estado, evolução e tendências no desenvolvimento tecnológico deste setor, bem como identificar os principais provedores e suas redes de colaboração.

Dessa forma, este artigo apresenta um estudo analítico dos dados de depósitos de patentes associados à Agricultura de Precisão, permitindo a elaboração de indicadores quantitativos e qualitativos de patentometria para responder às seguintes questões da pesquisa: (1) As tecnologias desenvolvidas para a Agricultura de Precisão têm crescido em termos de depósitos de patentes? (2) Quais os principais titulares e inventores das tecnologias, bem como os países em que os pedidos de patente são depositados? (3) Como os depósitos relativos à Agricultura de Precisão se organizam na base de patentes e quais os setores tecnológicos mais empregados no desenvolvimento de produtos e processos ao longo do tempo? (4) Quais as patentes mais relevantes, considerando as citações por outras tecnologias? (5) Quais as estruturas conceituais e sociais existentes na produção das tecnologias?

Este artigo está estruturado da seguinte forma: a seção 2 fornece uma revisão da literatura sobre a importância do monitoramento tecnológico a partir da análise de patentes; na seção 3 são discutidos os detalhes metodológicos; a seção 4 
apresenta os principais resultados obtidos a partir da análise de dados, abordando as cinco questões de pesquisa mencionadas anteriormente; finalmente, na seção 5, são apresentadas as conclusões e limitações do estudo, bem como sugestões para pesquisas futuras.

\section{Patentes e Monitoramento Tecnológico}

Os documentos de patentes dispõem de muitas informações tecnológicas e têm importante influência na inovação e no desenvolvimento tecnológico. A análise adequada transforma esses dados em informações sistemáticas e valiosas. Dessa forma, os dados patentários podem ser analisados de diversas formas para atender diferentes propósitos. No geral, os propósitos da análise de patentes envolvem: determinar a novidade em patentes, analisar tendências, prever desenvolvimentos tecnológicos, planejamento estratégico de tecnologia, identificar concorrentes tecnológicos, mapeamento das tecnologias, entre outros (Abbas et al., 2014; Chang et al., 2010).

O processo de análise de patentes é constituído por uma série de etapas, desde a extração de informações dos bancos de dados de patentes, até a análise e interpretação dos resultados. Comumente, a análise bibliométrica de patentes (patentometria) é mais usada nesse processo, a qual é possível identificar a atividade tecnológica, os provedores das tecnologias, os setores tecnológicos envolvidos e as tecnologias mais citadas. No entanto, os avanços no campo da análise de redes sociais propiciaram diversos estudos que empregaram técnicas de análise de redes para investigar e visualizar mais detalhadamente os dados disponíveis nas patentes, explicando a relação entre campos de tecnologia, titulares de patentes, inventores, etc. (Sternitzke et al., 2008).

Existem milhões de patentes espalhadas por diferentes bases de dados. Os repositórios de documentos de patentes mais populares são o Espacenet, do European Patent Office (EPO), o PatentScope, da World Intellectual Property Organization (WIPO), o United States Patent and Trademark Office (USPTO) e o Japan Patent Office (JPO) (Silva et al., 2020).

No entanto, vale destacar que os dados relativos às patentes em determinados domínios tecnológicos são difíceis de analisar devido ao volume cada vez maior de informações. Sendo assim, nem sempre é possível confiar totalmente no conhecimento e nas habilidades dos especialistas para analisar as patentes. Por outro lado, a utilização de ferramentas auxiliadas por computador no processo de análise de patentes pode automatizar diversas tarefas, reduzindo a carga de trabalho manual dos especialistas e acelerando o processo de análise para monitoramento das tecnologias (Abbas et al., 2014).

O monitoramento das tecnologias associadas à Agricultura de Precisão, a partir da análise de informações dos documentos de patentes, foi realizado neste estudo, no qual são apresentadas diversas ferramentas de software livre que apoiam o processo de análise bibliométrica de patentes, as técnicas de análise em mineração de texto e de visualização em redes sociais de cooperação.

\section{Dados e Métodos}

Considerando os objetivos, esta pesquisa adotou procedimentos metodológicos que envolveram aspectos descritivos e exploratórios, a partir de uma abordagem quantitativa e qualitativa. A abordagem quantitativa se deu por meio da análise patentométrica dos dados para mensurar a produção tecnológica no setor de Agricultura de Precisão. A abordagem qualitativa se deu por meio da análise de conteúdo das principais patentes recuperadas, atribuindo aos dados quantitativos significados mais amplos (Pereira, 2016).

Para responder às questões da pesquisa, o fluxo de trabalho do mapeamento tecnológico da Agricultura de Precisão foi dividido em seis estágios: (1) Estudo preliminar do tema e definição do escopo; (2) Pesquisa na base de dados Lens.org; (3) 
Exportação dos registros no formato CSV; (4) Agrupamento dos registros por família de patentes; (5) Indexação, limpeza e normalização dos dados; (6) Análise descritiva, mineração de dados e texto, visualização e discussão (Figura 1).

Figura 1 - Diagrama de fluxo da pesquisa.

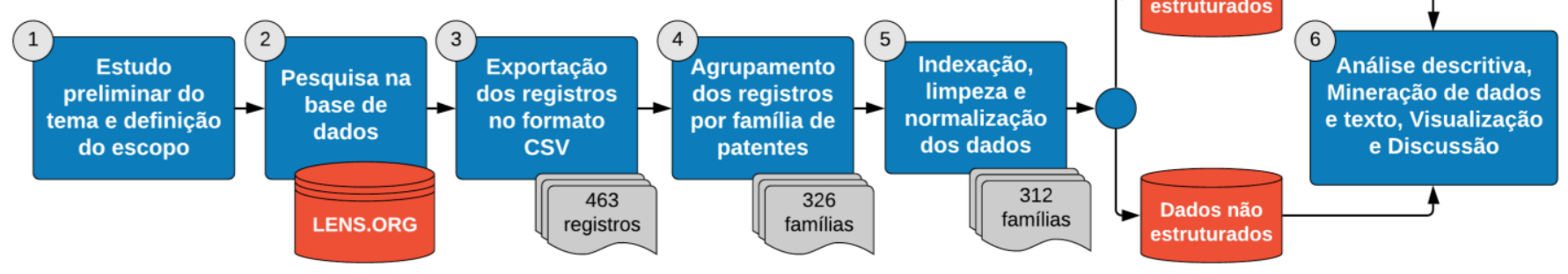

Fonte: Elaborada pelos autores.

No primeiro estágio, realizou-se uma revisão de literatura narrativa a partir de livros e artigos publicados em periódicos para fundamentação teórica do tema, evidenciando sua relevância e justificativa para o desenvolvimento deste estudo (seções 1 e 2). Os estágios 2 ao 5 serão detalhados na seção 3.1 (Coleta e tratamento de dados), enquanto que o estágio 6 será apresentado e discutido na seção 4 (Análise, visualização e discussão).

\subsection{Coleta e tratamento de dados}

Para uma análise de patentes, é fundamental obter acesso aos dados sobre as mesmas. Sendo assim, o segundo estágio do fluxo desta pesquisa refere-se à consulta e recuperação de informações da base de dados de patentes.

A maioria dos escritórios de patentes oferece acesso gratuito aos registros, mas na prática é mais conveniente utilizar ferramentas que indexam documentos de vários escritórios, permitindo diversas consultas específicas (Masiakowski \& Wang, 2013). Existem diversas bases de dados de patentes gratuitas e comerciais disponíveis, cada uma possui pontos fortes e fracos específicos. Este estudo priorizou a utilização de ferramentas de acesso livre, servindo como uma fonte de referência para demais monitoramentos tecnológicos em diferentes campos do conhecimento. Desta forma, o banco de dados The Lens (lens.org) foi definido para a busca.

The Lens é um projeto da Cambia, uma empresa social global sem fins lucrativos que se dedica a democratizar a solução de problemas usando ciência e tecnologia. Anteriormente conhecida como Patent Lens, essa ferramenta agrega mais de 225 milhões de trabalhos acadêmicos, mais de 127 milhões de registros de patentes globais e mais de 370 milhões de patentes de sequências de DNA, com metadados ricos, incluindo as pessoas e instituiç̃oes que geram esse conhecimento e as ligações entre elas, extraídas de diversas fontes de dados (The Lens, 2021).

Uma vez que a recuperação de dados deve ser auxiliada por definições e diretrizes de extração de dados registradas sob a forma de um protocolo (Brereton et al., 2007), foi elaborada uma estratégia de pesquisa avançada, combinando, por meio de operadores lógicos booleanos, a busca dos termos sinônimos da Agricultura de Precisão, em inglês, no título e resumo dos documentos de patentes (Quadro 1). 
Quadro 1 - Protocolo de busca de patentes.

\begin{tabular}{|l|l|}
\hline Termos & $\begin{array}{l}\text { Precision Agriculture, Precision Farming, Satellite Farming, Satellite Agriculture, Site Specific Crop } \\
\text { Management }\end{array}$ \\
\hline Campos & Título ou Resumo \\
\hline Período & Até 2020 \\
\hline Query & $\begin{array}{l}\text { title:("precision agriculture") OR title:("precision farming") OR title:("satellite farming") OR } \\
\text { title:("satellite agriculture") OR title:("site specific crop management") OR abstract:("precision } \\
\text { agriculture") OR abstract:("precision farming") OR abstract:("satellite farming") OR abstract:("satellite } \\
\text { agriculture") OR abstract:("site specific crop management") }\end{array}$ \\
\hline Stemming & Off \\
\hline Restrição 01 & Devem ter título e resumo \\
\hline Restrição 02 & Simple Families Patent \\
\hline
\end{tabular}

Fonte: Elaborada pelos autores.

A recuperação dos dados foi realizada em outubro de 2021 e se limitou aos registros de patentes que possuem título e resumo, publicados até o ano de 2020. O ano de 2021 foi excluído, uma vez que na época desta pesquisa os dados estariam incompletos para a análise. O processo de stemming foi desativado para evitar resultados fora do escopo da busca.

Foram identificados 463 registros de depósitos de patentes, os quais seguiram ao terceiro estágio para exportação dos dados (estruturados e não estruturados) no formato .csv (valores separados por vírgulas) para uso em outras ferramentas. Para melhorar a precisão do estudo, no quarto estágio os registros foram agrupados por família de patentes, ou seja, conjuntos de patentes depositadas em diferentes países que estão relacionados entre si por um ou vários depósitos de prioridade comum. Essa abordagem permite construir indicadores de patentes mais refinados, evitando a contagem dupla de invenções únicas (Martínez, 2011). Assim, este estudo resultou em 326 famílias de patentes associadas à Agricultura de Precisão.

No quinto estágio, foi realizada a indexação dos dados para limpeza e normalização. Limpar dados de patentes é uma das tarefas mais desafiadoras e demoradas envolvidas na análise de patentes. O Manual da WIPO sobre Análise de Patentes de Código Aberto recomenda aos analistas a ferramenta gratuita Open Refine, uma vez que esta é mais fácil e eficiente ao realizar tarefas de limpeza se comparada ao uso de planilhas eletrônicas. O Open Refine é um aplicativo instalado no computador, mas é executado em um navegador web sem a necessidade de conexão com a internet (WIPO, 2016).

Os dados indexados no Open Refine passaram por diversas transformações, incluindo: remoção de espaços em branco em torno do texto e caracteres duplicados, regularização de caracteres, definição do país de depósito para pedidos feitos via Tratado de Cooperação de Patentes (PCT), renomeação de colunas, remoção de dados desnecessários ao estudo e exclusão de redundâncias. Após o processo de limpeza, foram identificadas 312 famílias de patentes que foram estudadas sob diferentes níveis de análise.

Definido o conjunto de dados para análise, as informações sobre as Classificações Internacionais de Patentes (IPC) de cada registro foram fragmentadas em seção, classe, subclasse, grupo e subgrupo. Da mesma forma, foi feita a fragmentação dos dados dos requerentes e inventores para investigar as produções individuais e as colaborações. Também foi realizado um processo de normalização desses nomes para encontrar grupos de valores diferentes que podem ser representações alternativas do mesmo nome. Para isso, o Open Refine dispõe de seis algoritmos de clusterização que podem ser configurados em termos de critérios de correspondência entre os nomes dos inventores ou requerentes (Ham, 2013; Sternitzke et al., 2008). Por fim, o estágio de indexação, limpeza e normalização gerou diversas tabelas de dados estruturados e não estruturados sob diferentes aspectos que foram preparados para análise na seção seguinte. 


\section{Análise, Visualização e Discussão}

Os gráficos apresentados neste estudo foram desenvolvidos a partir da ferramenta Tableau Public, uma versão gratuita do Tableau Desktop que fornece uma introdução prática muito poderosa para análise e visualização de dados de patentes e também indicada como opção de ferramenta de análise visual pelo Manual da WIPO sobre Análise de Patentes de Código Aberto (Tableau, 2021; WIPO, 2016).

Foram analisadas neste estudo um total de 312 famílias de patentes relacionadas à Agricultura de Precisão (AP), as quais foram publicadas no período de 1995 a 2020 (26 anos). Este estudo considera para efeitos de análise a data de publicação dos pedidos pelos escritórios de patentes. A análise da família de patente considera o depósito prioritário. Sendo assim, ao se referir à família da patente, poderá ser utilizado apenas o termo patente ou equivalente.

Na Figura 2 é apresentado o gráfico de evolução das publicações ao longo do tempo, considerando a quantidade por ano e acumulada. Foram realizadas em média 12 publicações por ano, com uma taxa anual de crescimento em torno de 16,5\%. No entanto, a produção tecnológica referente à Agricultura de Precisão foi bastante tímida na maioria do tempo. Foi a partir de 2013 que houve um aumento significativo no número de depósitos, não é à toa que os pedidos de patentes publicados na última década somam $86 \%$ do total.

Figura 2 - Evolução das publicações de patentes relacionadas à Agricultura de Precisão.

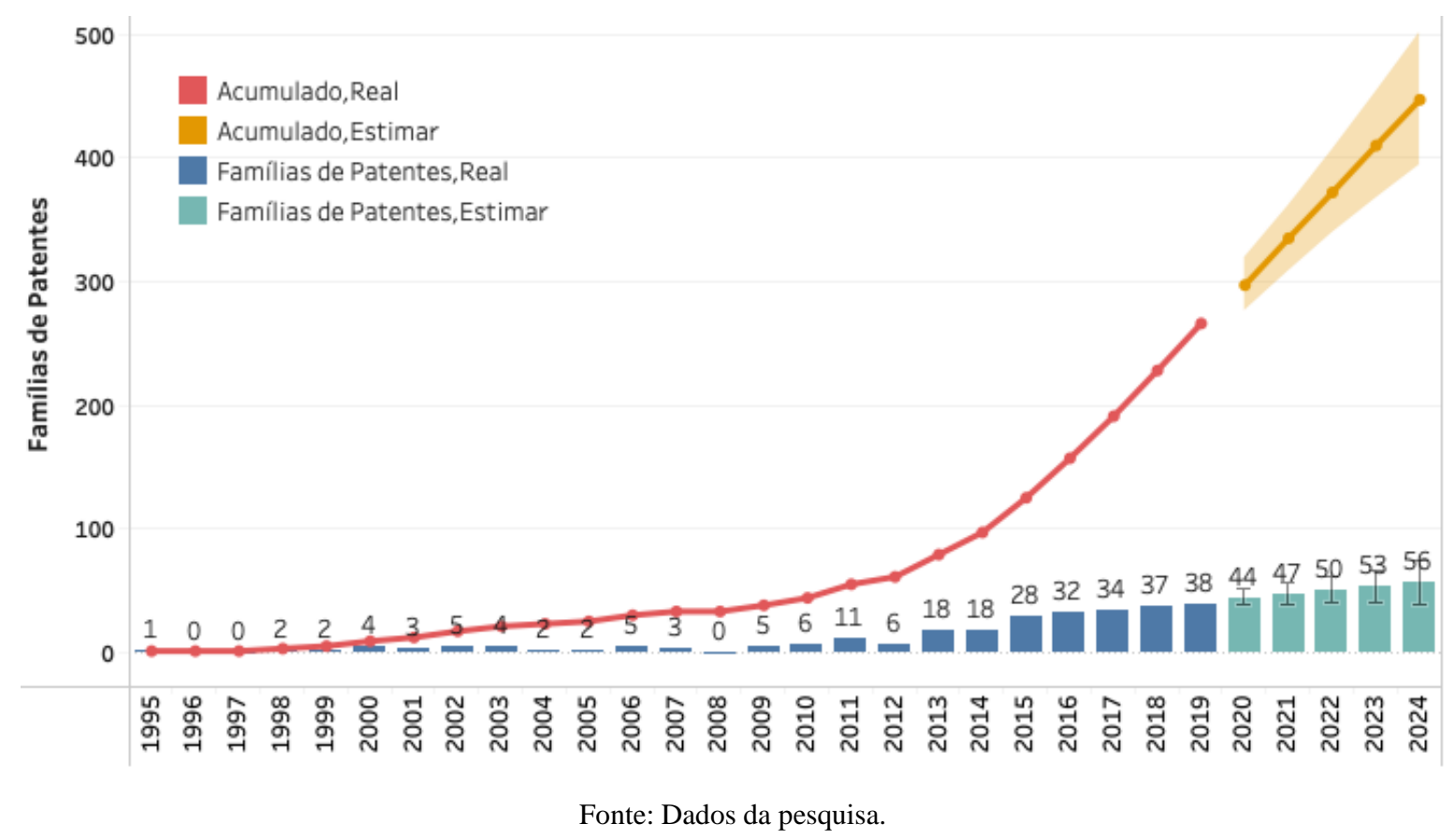

O primeiro registro foi publicado em novembro de 1995 nos Estados Unidos pela TRW Inc., uma corporação americana fundada em 1901 e posteriormente incorporada. Foi pioneira em diversos campos tecnológicos e na patente mencionada desenvolveu um sistema de mapeamento e análise que inclui um dispositivo para gerar dados de imagem espectral relacionados a pelo menos uma das características de estresse da vegetação e do solo. A patente foi concedida na época, mas já atingiu a data de validade e não está mais em vigor.

A ferramenta Tableau Public permitiu estimar as tendências futuras de publicações, tanto por ano como acumulado. $\mathrm{O}$ gráfico confirma a tendência de crescimento, podendo acumular nos próximos quatro anos um total de 400 a 500 pedidos de patentes publicados. 
Neste último estágio de análise, visualização e discussão, foi articulada inicialmente uma análise descritiva dos dados do estudo (seção 4.1), levando em consideração as principais unidades de análise do monitoramento tecnológico: países (onde é publicado o pedido), inventores e requerentes (atores que desenvolvem as tecnologias), setores tecnológicos (do que trata as invenções) e bases tecnológicas (patentes mais citadas).

Em seguida, ferramentas e técnicas de mineração de texto foram utilizadas para descobrir padrões e tendências a partir de informações não estruturadas das patentes (título e resumo). A análise de cluster ou agrupamentos permitiu identificar as patentes mais semelhantes entre si, assim como identificou os tópicos mais relevantes das tecnologias desenvolvidas no campo da Agricultura de Precisão (seção 4.2).

Por fim, realizou-se a análise de rede de patentes, enfatizando as estruturas conceituais e as relações que conectam as posições sociais de inventores e requerentes do campo tecnológico da AP (seção 4.3).

\subsection{Análise descritiva dos dados}

A análise descritiva teve o objetivo de resumir, sumarizar e investigar o comportamento dos registros bibliográficos das patentes identificadas no estudo e apresentá-los por meio de tabelas de frequência, gráficos e medidas de resumo numérico. Na Tabela 1 é apresentado um resumo dos principais resultados da análise descritiva.

Conforme mostrado na Tabela 1, as 312 patentes foram depositadas em 23 diferentes países por 303 requerentes distintos e um total de 968 inventores atuaram no desenvolvimento das tecnologias associadas à Agricultura de Precisão (AP). O número de aparições de requerentes (394) maior sugere depositantes com mais de uma patente neste campo. Da mesma forma, as aparições dos inventores (1175) demonstram a participação de inventores em várias tecnologias ligadas à AP. Os dados demonstram que o Índice de Colaboração dos requerentes e dos inventores são 1,26 e 3,77, respectivamente. Ou seja, essa é uma média da quantidade de requerentes e inventores encontrados por documento de patente.

Tabela 1 - Principais informações sobre os dados do estudo.

\begin{tabular}{lc}
\hline Tópico & \\
\hline Período & $1995-2020$ \\
Anos & 26 \\
Famílias de Patentes & 312 \\
Média de patentes por ano & 12 \\
Países de jurisdição & 23 \\
Média de citações por patente & 7,15 \\
Requerentes distintos & 303 \\
Aparições de requerentes (Co-requerentes) & 394 \\
Patentes por requerente & 1,03 \\
Índice de Colaboração dos requerentes & 1,26 \\
Inventores distintos & 968 \\
Aparições de inventores (Co-inventores) & 1175 \\
Patentes por inventor & 0,32 \\
Índice de Colaboração dos inventores & 3,77 \\
\hline
\end{tabular}

Fonte: Dados da pesquisa.

Uma das áreas importantes no monitoramento das tecnologias é o estudo da produção tecnológica dos países. Na Figura 3, são apresentados os 23 países identificados na pesquisa e suas respectivas quantidades de depósitos de patentes, dos quais se destacam a China com alta concentração de pedidos de patentes depositados (185), representando 59,3\% do total de 
patentes publicadas, os Estados Unidos com 71 patentes (22,8\%) e Rússia com 12 patentes (3,8\%). Os demais países possuem cinco ou menos pedidos depositados e juntos somam $14 \%$ do total.

Figura 3 - Países nos quais os depósitos de patente referentes à AP foram realizados.

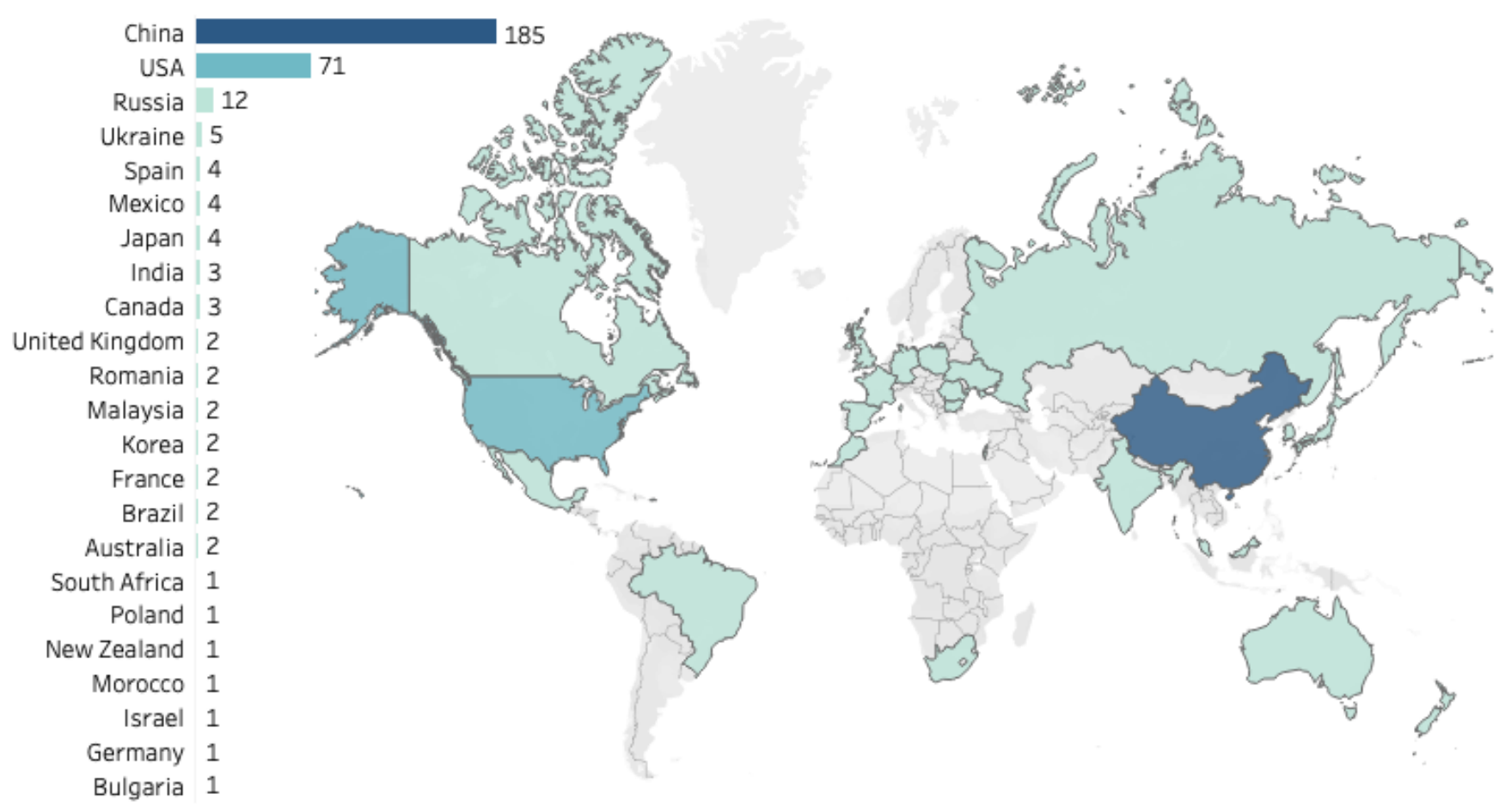

Fonte: Dados da pesquisa.

Para se comparar os depósitos realizados nos principais países ao longo do tempo, na Figura 4 é apresentada a produção tecnológica nos países que tiveram três ou mais depósitos realizados, resultando em nove regiões. Observa-se que a China, apesar de ser a maior detentora dos depósitos de patentes no campo da Agricultura de Precisão, realizou a primeira publicação em 2002, retornando a publicar em 2006. Porém, foi a partir de 2009 que houve publicações constantes e crescentes que garantiram o destaque neste estudo. Por outro lado, os Estados Unidos apresentaram maior uniformidade no número de publicações anuais, sendo este o primeiro país a registrar uma patente no setor. Já a Rússia, terceiro maior país depositante, realizou a primeira publicação em 2007, mas foi a partir de 2014 que se manteve consistente.

Ao analisar a quantidade de requerentes das patentes, constatou-se a existência de 303 entidades distintas (Tabela 1). Vale ressaltar que o requerente é o titular ou proprietário da patente, que pode ser o próprio inventor, uma empresa, um centro de pesquisa ou uma universidade, aos quais é concedido o direito de impedir o uso e exploração de sua criação por terceiros, bem como sua comercialização. A média de patentes por requerente de 1,03 reforça que a maior parte dos titulares $(84,5 \%)$ detêm apenas um depósito relacionado à AP. 
Figura 4 - Depósitos nos principais países ao longo do tempo.

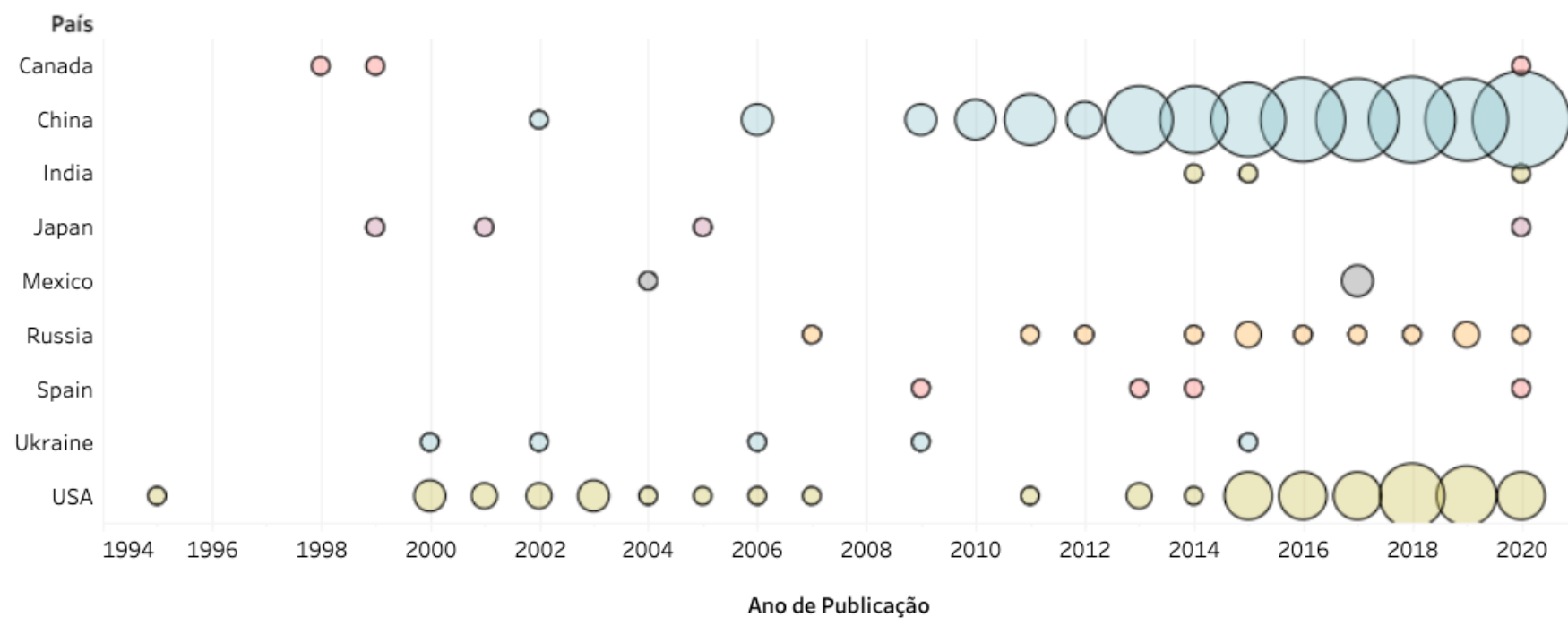

Fonte: Dados da pesquisa.

Os principais titulares das tecnologias identificadas neste estudo de monitoramento, considerando no mínimo cinco depósitos, são apresentados na Figura 5, os quais se destaca a Iteris Inc., uma empresa americana que fornece software, serviços e sensores para diversas atividades, entre elas análise de clima e agricultura. Além de empresas, também se destacam entre os maiores depositantes, universidades chinesas e titulares-inventores, como é o caso de Harris Lee Cohen que possui 6 invenções no setor.

Figura 5 - Principais requerentes e inventores das tecnologias da Agricultura de Precisão.
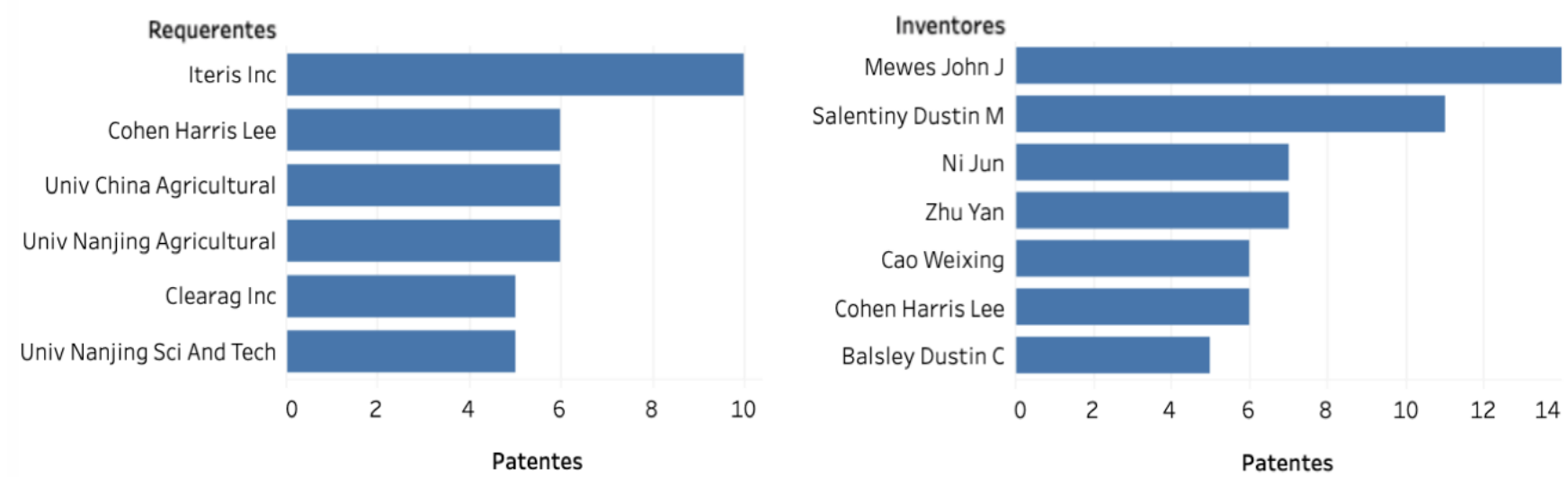

Fonte: Dados da pesquisa.

Quanto aos criadores das tecnologias da Agricultura de Precisão, este estudo revelou a participação de 968 inventores (Tabela 1), entre os quais se destacam John J. Mewes com 14 invenções. Boa parte dessas invenções foram desenvolvidas com o segundo inventor mais produtivo, Dustin M. Salentiny (11 patentes), e são de titularidade das empresas Iteris Inc. e/ou ClearAg Inc., que estão entre os maiores detentores das tecnologias encontradas neste estudo (Figura 5).

Uma das leis clássicas da bibliometria é a Lei de Lotka a qual afirma que a quantidade Y de autores que fazem X publicações sobre um determinado tema é aproximadamente $1 / \mathrm{X}^{2}$ daqueles que publicam apenas uma vez ou, de forma geral, $\mathrm{Y}=\mathrm{C} / \mathrm{X}^{\alpha}$, onde $\mathrm{C}$ e $\alpha$ são definidos de acordo com os dados observados (Lotka, 1926). Estudos demonstram que a Lei de 
Lotka apresenta aplicabilidade favorável na literatura de patentes (Yang et al., 2014). Dessa forma, foi realizada a distribuição de frequências da produtividade tecnológica dos inventores e assim verificou-se a aplicabilidade da lei. O percentual de inventores com mais de 10 patentes está em torno de $0,2 \%$, enquanto mais de $86 \%$ participaram de apenas uma invenção, conforme apresentado na Figura 6.

Figura 6 - Lei de Lotka aplicada à produtividade tecnológica dos inventores.

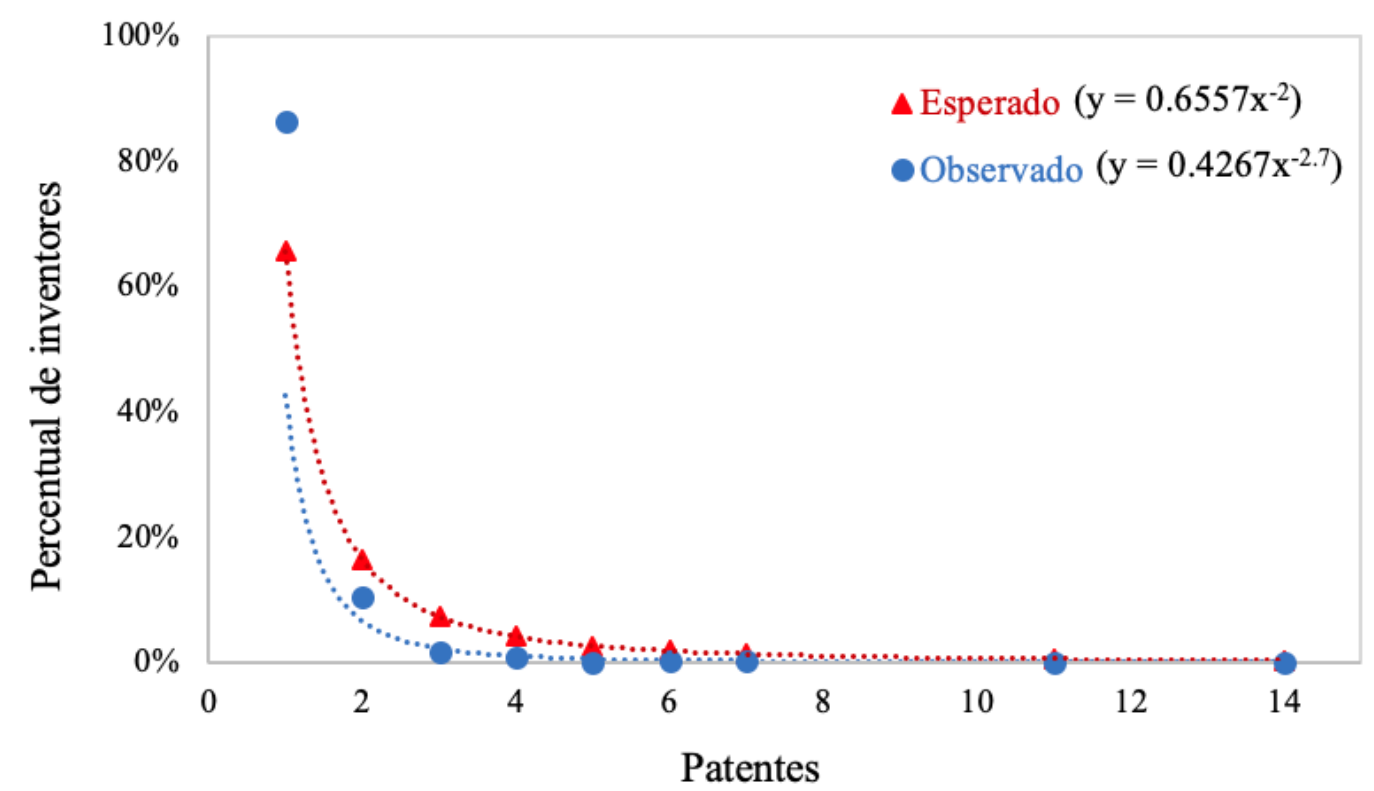

Fonte: Dados da pesquisa.

Os produtos e processos desenvolvidos no âmbito da Agricultura de Precisão (AP) podem abordar vários setores tecnológicos, uma vez que a adoção da AP envolve a criação de um sistema complexo de softwares e máquinas para monitorar e avaliar os dados coletados de todo processo de produção agrícola. Uma forma de identificar esses setores é por meio da Classificação Internacional de Patentes (IPC) que codifica a aplicação e a função de determinada patente. A IPC é publicada pela Organização Mundial de Propriedade Intelectual e possui uma estrutura hierárquica de cinco níveis. Seguindo essa classificação, entre as 312 famílias de patentes analisadas foram identificadas 7 seções, 29 classes, 75 subclasses, 184 grupos e 348 subgrupos.

Com o propósito de apresentar uma visão geral das áreas tecnológicas das patentes da Agricultura de Precisão, no Quadro 2 são apresentadas as principais classes e subclasses encontradas por seção, tendo como destaque as relacionadas com agricultura (41,4\% das patentes), cálculo (33,7\%), medição (28,5\%) e comunicação $(12,8 \%)$. Essas classes estão diretamente ligadas à filosofia da Agricultura de Precisão e constituem sua base tecnológica. Outras classificações com menor participação representam produtos ou processos especializados, a exemplo das classes de aeronaves, pulverização, engenharia hidráulica, sistemas de engrenagens, fertilizantes, atuadores por pressão de fluidos, perfuração do solo, entre outras. 
Quadro 2 - Principais classes e subclasses das patentes relacionadas à Agricultura de Precisão.

\begin{tabular}{|c|c|c|}
\hline \multicolumn{3}{|c|}{ SEÇÃO G - FÍSICA (66.99\%) } \\
\hline \multirow{2}{*}{$\begin{array}{c}\text { G06 } \\
(33.65 \%)\end{array}$} & \multicolumn{2}{|c|}{ Cômputo; Cálculo ou contagem } \\
\hline & G06F & Processamento elétrico de dados digitais. \\
\hline \multirow{2}{*}{$\begin{array}{c}\text { G01 } \\
(28.53 \%)\end{array}$} & \multicolumn{2}{|c|}{ Medição; Teste } \\
\hline & G01N & Investigação ou análise dos materiais pela determinação de suas propriedades químicas ou físicas. \\
\hline \multicolumn{3}{|c|}{ SEÇÃO A - NECESSIDADES HUMANAS (41.35\%) } \\
\hline \multirow{2}{*}{$\begin{array}{c}\text { A01 } \\
(41.35 \%)\end{array}$} & \multicolumn{2}{|c|}{ Agricultura; Silvicultura } \\
\hline & $\mathrm{A} 01 \mathrm{C}$ & Plantio; semeadura; fertilização. \\
\hline \multicolumn{3}{|c|}{ SEÇÃO H - ELETRICIDADE (15.06\%) } \\
\hline \multirow{2}{*}{$\begin{array}{c}\text { H04 } \\
(12.82 \%)\end{array}$} & \multicolumn{2}{|c|}{ Técnica de comunicação elétrica } \\
\hline & H04W & Redes de comunicação sem fio. \\
\hline \multirow{2}{*}{$\begin{array}{c}\text { H02 } \\
(1,60 \%)\end{array}$} & \multicolumn{2}{|c|}{ Produção, conversão ou distribuição de energia elétrica } \\
\hline & $\mathrm{H} 02 \mathrm{~S}$ & Geração de energia elétrica pela conversão da radiação infravermelha, luz visível ou luz ultravioleta. \\
\hline \multicolumn{3}{|c|}{ SEÇÃO B - OPERAÇÕES DE PROCESSAMENTO; TRANSPORTE $(8.97 \%)$} \\
\hline \multirow{2}{*}{$\begin{array}{c}\text { B64 } \\
(4.81 \%)\end{array}$} & \multicolumn{2}{|c|}{ Aeronaves; Aviação; Cosmonáutica } \\
\hline & B64D & Equipamento apropriado em ou para aeronaves. \\
\hline \multirow{2}{*}{$\begin{array}{c}\text { B05 } \\
(1,60 \%)\end{array}$} & \multicolumn{2}{|c|}{ Pulverização ou atomização em geral; aplicação de materiais fluentes a superfícies, em geral } \\
\hline & B05B & Aparelhos de pulverização; aparelhos de atomização; bocais. \\
\hline \multicolumn{3}{|c|}{ SEÇÃO E - CONSTRUÇÕES FIXAS (2.24\%) } \\
\hline \multirow{2}{*}{$\begin{array}{c}\mathbf{E 0 2} \\
(1.28 \%)\end{array}$} & \multicolumn{2}{|c|}{ Engenharia hidráulica; Fundações; Terraplenagem } \\
\hline & E02B & Engenharia hidráulica. \\
\hline \multirow{2}{*}{$\begin{array}{c}\text { E21 } \\
(0.32 \%)\end{array}$} & \multicolumn{2}{|c|}{ Perfuração do solo; mineração } \\
\hline & E21B & Perfuração do solo ou rocha; obtenção de óleo, gás, água, materiais solúveis ou fundíveis; etc. \\
\hline \multicolumn{3}{|c|}{ SEÇÃO C - QUÍMICA; METALURGIA (1.92\%) } \\
\hline \multirow{2}{*}{$\begin{array}{c}\text { C05 } \\
(0.96 \%)\end{array}$} & \multicolumn{2}{|c|}{ Fertilizantes; sua fabricação } \\
\hline & $\mathrm{C} 05 \mathrm{C}$ & Fertilizantes nitrogenados. \\
\hline \multirow{2}{*}{$\begin{array}{c}\text { C12 } \\
(0.64 \%)\end{array}$} & \multicolumn{2}{|r|}{ Bioquímica; cerveja; álcool; vinho; vinagre; microbiologia; enzimologia; engenharia genética ou de mutação } \\
\hline & $\mathrm{C} 12 \mathrm{~N}$ & Propagação, conservação, ou manutenção de microrganismos; engenharia genética ou de mutações. \\
\hline \multicolumn{3}{|c|}{ SEÇÃO F - ENGENHARIA MECÂNICA; ILUMINAÇÃO; AQUECIMENTO (1.60\%) } \\
\hline \multirow{2}{*}{$\begin{array}{c}\text { F16 } \\
(1.28 \%)\end{array}$} & \multicolumn{2}{|r|}{ Elementos ou unidades de engenharia; Medidas gerais para assegurar $O$ funcionamento efetivo de máquinas } \\
\hline & F16H & Sistemas de engrenagens. \\
\hline F15 & Atuador & por pressão de fluidos; Hidráulica ou Pneumática em geral \\
\hline$(0.32 \%)$ & F15B & Sistemas que funcionam por meio de fluidos em geral; atuadores por pressão de fluidos. \\
\hline
\end{tabular}

Fonte: Dados da pesquisa.

Para uma análise mais específica, foram investigados os principais subgrupos da classificação de patentes associadas à Agricultura de Precisão (AP) ao longo do tempo (Figura 7). Umas das áreas tecnológicas mais populares identificadas (A01B 79/00 - Métodos para preparar o solo com uso de máquinas) esteve presente no primeiro pedido de patente publicado em 1995 e nem todos os principais subgrupos IPC foram abordados de forma consistente desde o início. Isso demonstra que as patentes se concentraram inicialmente em poucos setores tecnológicos, mas na última década a AP adotou novas tecnologias e expandiu seus campos de atuação. 
Figura 7 - Evolução dos principais subgrupos das patentes associadas à Agricultura de Precisão.

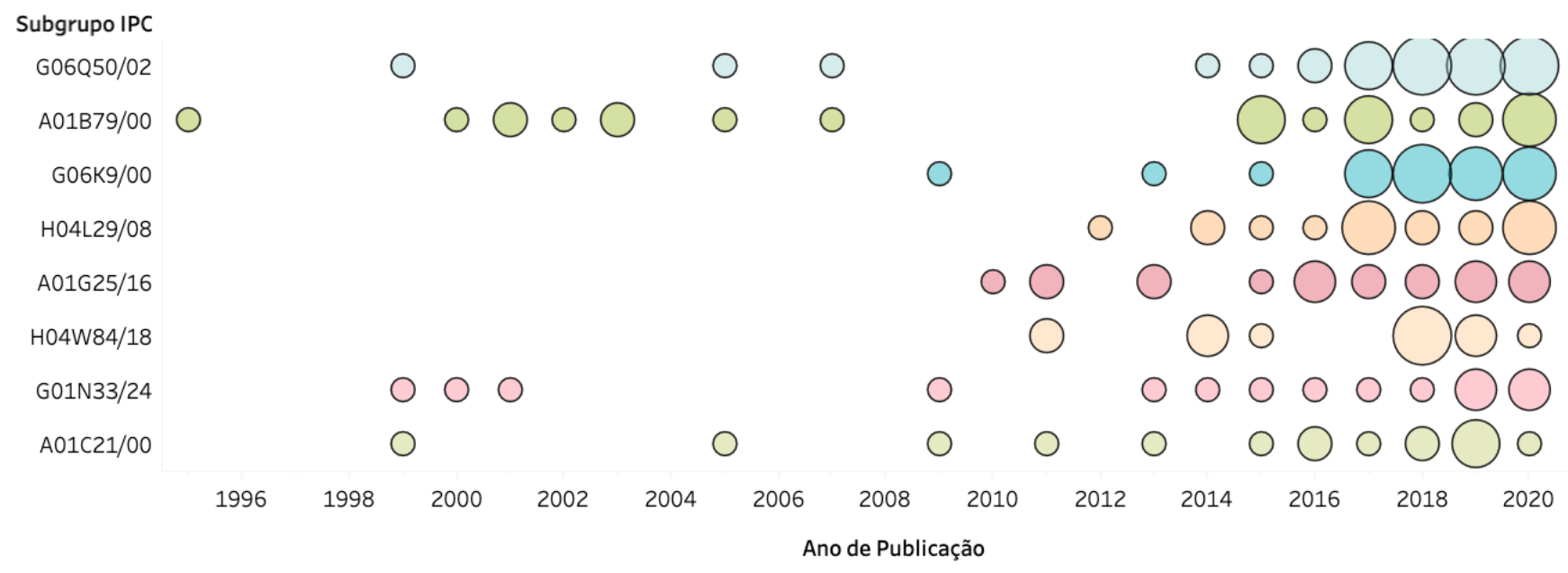

Fonte: Dados da pesquisa.

Ao analisar os subgrupos da Classificação Internacional de Patentes (IPC) em paralelo com os depositantes das patentes associadas à Agricultura de Precisão, é possível traçar o perfil de atuação tecnológica dos principais provedores da tecnologia. Na Figura 8 são apresentados os principais requerentes, considerando no mínimo três ocorrências do subgrupo IPC.

Figura 8 - Campos tecnológicos das patentes associadas a AP para os principais depositantes.

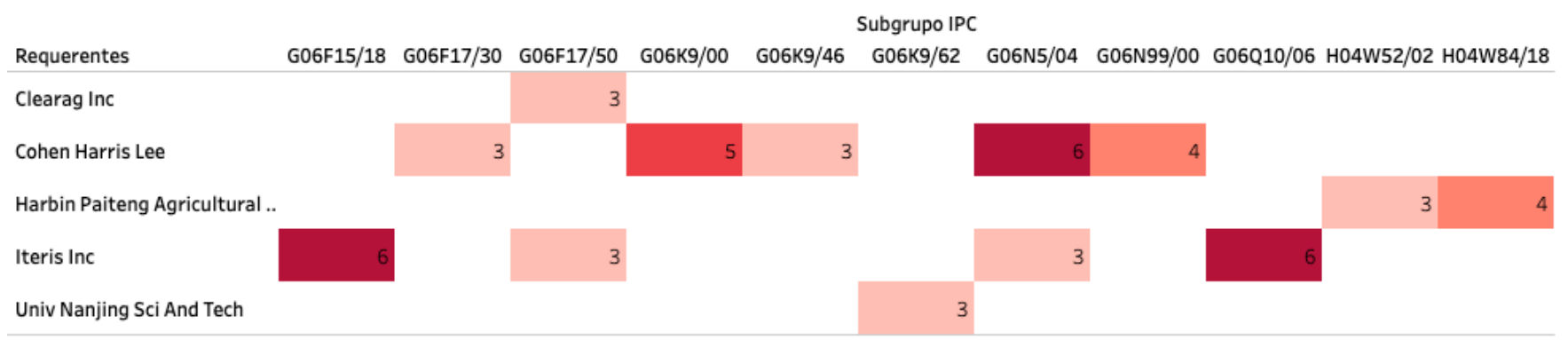

Fonte: Dados da pesquisa.

Nota-se que o maior depositante do setor de AP, a empresa americana Iteris Inc. (apresentada na Figura 5) focou seus produtos nas áreas de Machine Learning (G06F 15/18) e Sistemas de Gerenciamento (G06Q 10/06). O segundo maior depositante Harris Lee Cohen, que também é o próprio inventor, focou seus esforços nos Métodos ou dispositivos de inferência (G06N 5/04) e em Métodos para leitura e identificação de padrões (G06K 9/00). Com relação às universidades, a Nanjing University of Science and Technology (NJUST) concentra suas tecnologias para a Agricultura de Precisão nos Métodos eletrônicos de reconhecimento de padrões (G06K 9/62).

A análise descritiva também envolve a identificação das patentes mais citadas de determinado campo de estudo, uma vez que as patentes altamente citadas revelam produtos e serviços importantes, estabelecendo uma base tecnológica das patentes (Chang et al., 2010). Em média, uma patente associada à Agricultura de Precisão é citada por 7,15 patentes (Tabela 1), sendo que a maioria possui uma ou nenhuma citação. Na Tabela 2, são apresentadas as dez patentes mais citadas por outros depósitos, as quais possuem mais de 40 citações. 
Tabela 2 - Patentes de Agricultura de Precisão mais citadas por outras tecnologias.

\begin{tabular}{llc}
\hline Número & Título & Citações \\
\hline US 5467271 A & Mapping And Analysis System For Precision Farming Applications & 375 \\
US 20030187560 A1 & $\begin{array}{l}\text { Methods And Apparatus For Precision Agriculture Operations Utilizing } \\
\text { Real Time Kinematic Global Positioning System Systems }\end{array}$ & 170 \\
US 6016713 A & Soil Sampling "on The Fly" & 135 \\
US 6327569 B1 & System And Methods For Real Time Linkage Between Harvest & 89 \\
US 6501422 B1 & $\begin{array}{l}\text { Precise Parallel Swathing Guidance Via Satellite Navigation And Tilt } \\
\text { Measurement }\end{array}$ & 86 \\
US 20020038307 A1 & Systems And Methods For Knowledge Discovery In Spatial Data \\
US 6510367 B1 & $\begin{array}{l}\text { Delay Coordinating System For A System Of Operatively Coupled } \\
\text { Agricultural Machines }\end{array}$ & 81 \\
US 20160378086 A1 & Control System Used For Precision Agriculture And Method Of Use & 69 \\
US 20140263822 A1 & Vertical Take Off And Landing Autonomous/semiautonomous/remote \\
Controlled Aerial Agricultural Sensor Platform & 51 \\
\hline
\end{tabular}

Fonte: Dados da pesquisa.

Observa-se que as três patentes mais citadas possuem grande relevância para o campo da Agricultura de Precisão, visto que foram citadas mais de 100 vezes, com destaque para a publicação "Mapping And Analysis System For Precision Farming Applications", com 375 citações na data em que a pesquisa foi realizada, que por sua vez foi também o primeiro registro patente publicado na área. Essa patente foi concedida nos Estados Unidos em 1995 e atualmente possui status expirado. A segunda patente mais citada foi publicada em 2003 e apresenta a reivindicação de um veículo com aparelho de posicionamento preciso em tempo real para Agricultura de Precisão. Além de ser bastante citada, esta patente cita outras 39 patentes anteriores em seu estado da técnica. Já a terceira patente, publicada em 2000, consiste em um sistema de coleta de amostras georreferenciadas do solo. Além de ser citada por 135 patentes, a mesma cita patentes anteriores e trabalhos acadêmicos em sua publicação.

\subsection{Mineração de texto e clusterização}

Os documentos de patentes dispõem de vários tipos de conteúdos, como dados estruturados e não estruturados. Os dados não estruturados dos depósitos de patentes compreendem os textos narrativos do título, resumo, reivindicações e descrição. A natureza textual desses dados torna a extração de informações mais difícil em comparação aos dados estruturados. Para isso, é necessário o uso de ferramentas de mineração de texto (text mining) que possuem recursos de segmentação de dados textuais em estruturas significativas.

O aproveitamento adequado dos textos dos documentos de patentes pode complementar as interpretações derivadas da análise descritiva. A saída visual dos dados não estruturados de patentes geralmente é representada na forma de mapas e clusters de patentes. Neste estudo, ferramentas e técnicas de mineração de texto que utilizam abordagens baseadas em Processamento de Linguagem Natural (PLN) foram utilizadas para descobrir padrões e tendências a partir de informações não estruturadas das patentes. 
Inicialmente, a ferramenta Orange foi utilizada para geração de nuvens de palavras do título e do resumo das patentes. Orange é um pacote de aprendizado de máquina e mineração de dados para análise por meio de scripts Python e programação visual (Demsar et al., 2013). Durante o pré-processamento dos textos, foram elencadas as palavras a serem removidas da análise por serem sinônimas às palavras-chaves da pesquisa, além das stopwords previamente definidas na ferramenta para a língua inglesa.

Na Figura 9, são apresentadas as 50 palavras mais frequentes nos títulos e nos resumos das patentes, respectivamente. No título, há predominância dos termos: dispositivo, monitoramento, colheita, solo, campo, controle e dados. Em menor número, encontram-se: hiperespectral, crescimento, clima, irrigação, etc. Nos resumos foram encontrados termos semelhantes e outros menos comuns como sensores, fertilizantes, veículos, wireless, entre outros.

Figura 9 - Nuvem de palavras encontradas no Título (à esquerda) e Resumo (à direita) das patentes.
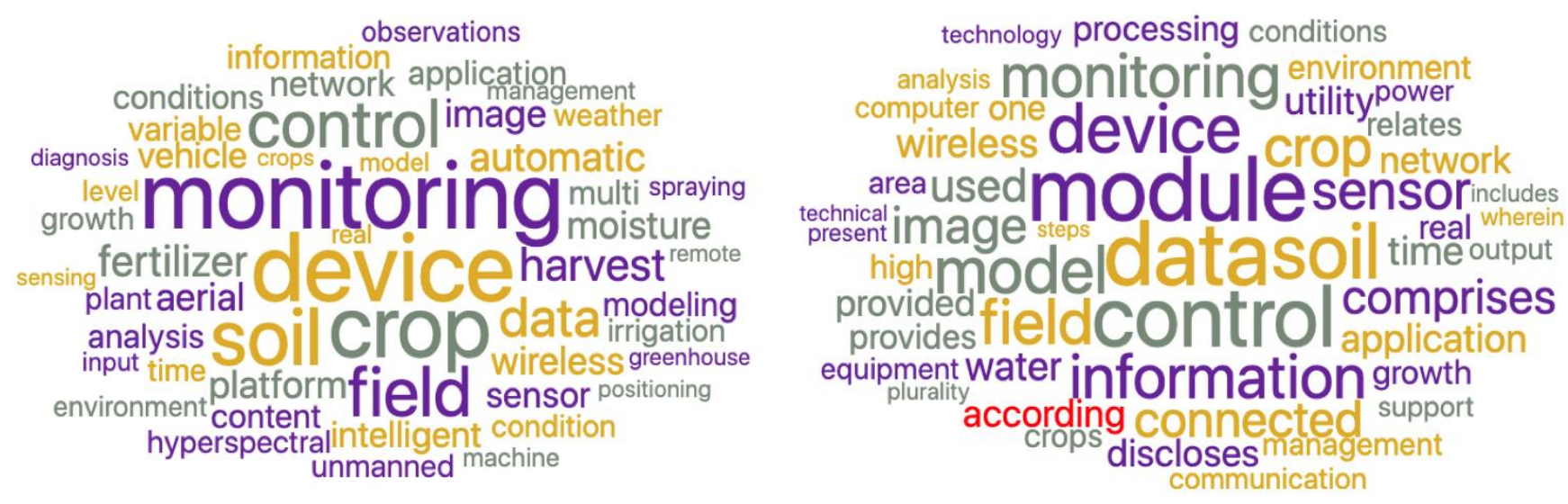

Fonte: Dados da pesquisa.

Com o objetivo de gerar agrupamentos de patentes com temas afins a partir dos dados não estruturados dos títulos e resumos das patentes na área de Agricultura de Precisão, este estudo utilizou a ferramenta Carrot2 Clustering Workbench. O projeto Carrot2 é um mecanismo de clusterização Open Source capaz de descobrir automaticamente grupos de documentos relacionados e rotulá-los com palavras-chave ou frases curtas, por meio de algoritmos de clustering (Carrot2, 2021).

Foram criados dois agrupamentos a partir dos algoritmos Lingo e K-means, respectivamente (Figura 10). O algoritmo Lingo extrai frases frequentes de documentos de entrada para determinar o seu conteúdo, enfatizando a qualidade da descrição do cluster. O algoritmo K-means é baseado em distância, onde calcula-se as distâncias para atribuir um ponto a um cluster. Produz descrições no estilo bag-of-words (Osiński et al., 2004).

O agrupamento utilizando Lingo encontrou 51 clusters, entre eles, "fertilização precisa", "válvula de controle", "veículo aéreo não tripulado", "sensoriamento remoto", "processamento de imagem", "rede de sensores sem fio", "calibração automática", entre outros. Por outro lado, o algoritmo K-means encontrou 25 agrupamentos, entre eles: "colheita, condições, clima"; "solo, sem fio, rede"; "imagem, hiperespectral, obtida"; "aéreo, não tripulado, arroz"; "pulverização, válvula, pesticida", entre outros. O Carrot2 utiliza a ferramenta de visualização Foam Tree Visualization (Figura 10). Os agrupamentos corroboram com os dados sobre as principais classes e subclasses das patentes relacionadas à Agricultura de Precisão, apresentadas no Quadro 2. 
Figura 10 - Agrupamentos de patentes: Lingo (à esquerda) e K-means (à direita).
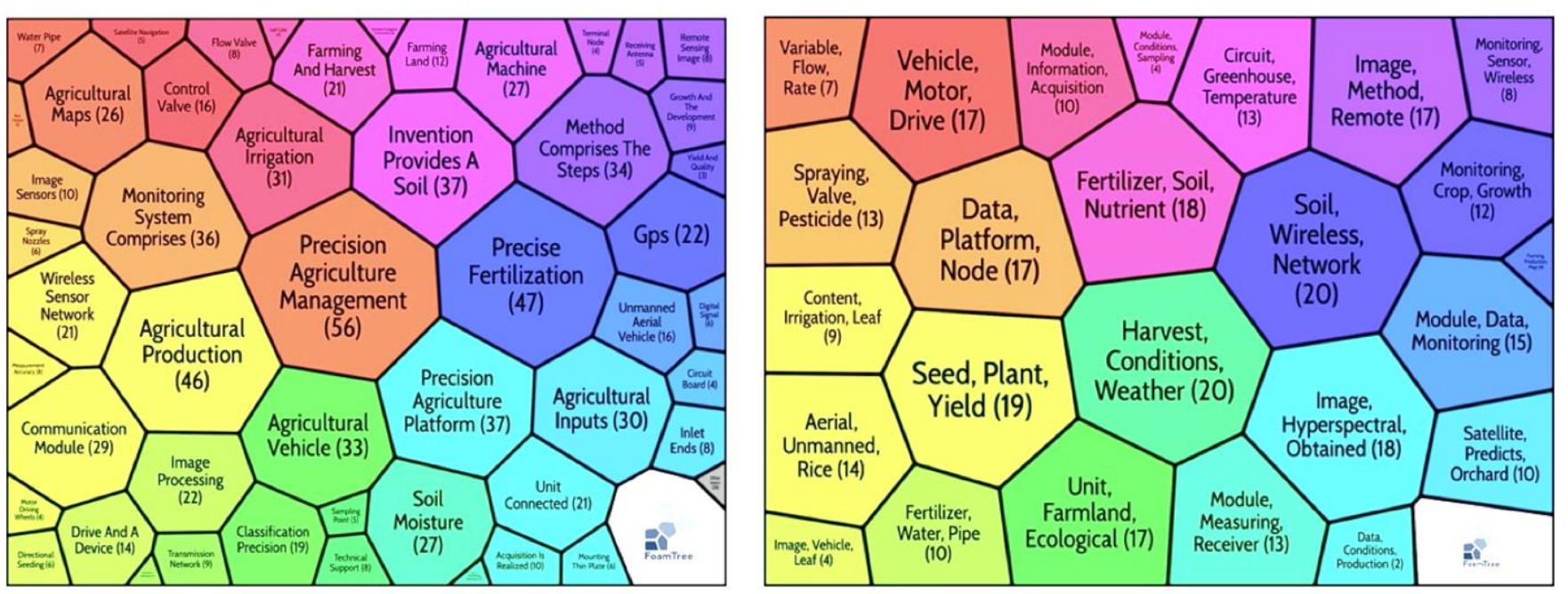

Fonte: Dados da pesquisa.

\subsection{Análise das redes de patentes}

A análise de redes sociais explora, a princípio, a relação entre seres humanos, mas também é bastante aplicada à modelagem de relacionamentos técnicos e a dados bibliométricos, como os dados de documentos de patentes. As diversas ferramentas de softwares facilitam a visualização, análise e interpretação de dados de cooperação entre setores tecnológicos (IPC), requerentes (titulares das tecnologias), inventores e outros aspectos. A análise de redes de patentes enfatiza as relações existentes em determinado domínio tecnológico, descrevendo as estruturas sociais e seus componentes (Sternitzke et al., 2008).

Neste estudo, foram adotados dois softwares Open Source para criação das redes de patentes. O Pajek, programa para análise e visualização de grandes redes que possuam milhares ou até milhões de nós (Batagelj \& Mrvar, 1998) e o Gephi, software para visualização e manipulação de rede e outros tipos de sistemas complexos (Bastian et al., 2009). O Pajek foi utilizado para criação dos dados de rede no formato .NET que posteriormente foram importados pelo Gephi para visualização dinâmica da rede, permitindo identificar padrões e tendências de forma mais intuitiva que o software anterior.

Na Figura 11, é apresentada a rede de coocorrência das classificações (IPC) nas patentes analisadas sobre a Agricultura de Precisão. Cada nó da rede representa um campo tecnológico, ou seja, um subgrupo da IPC, e as arestas correspondem as coocorrências com outros campos tecnológicos na mesma patente. O tamanho do nó define o grau de ocorrência, isto é, quanto maior o tamanho, mais vezes o campo da tecnologia está associado a outros. Assim também, a espessura da aresta define o grau de relacionamento entre dois subgrupos. Para melhorar a visibilidade da rede, foram considerados apenas os campos tecnológicos com mais de dez relacionamentos. 
Figura 11 - Rede de cooperação entre campos tecnológicos (IPC).

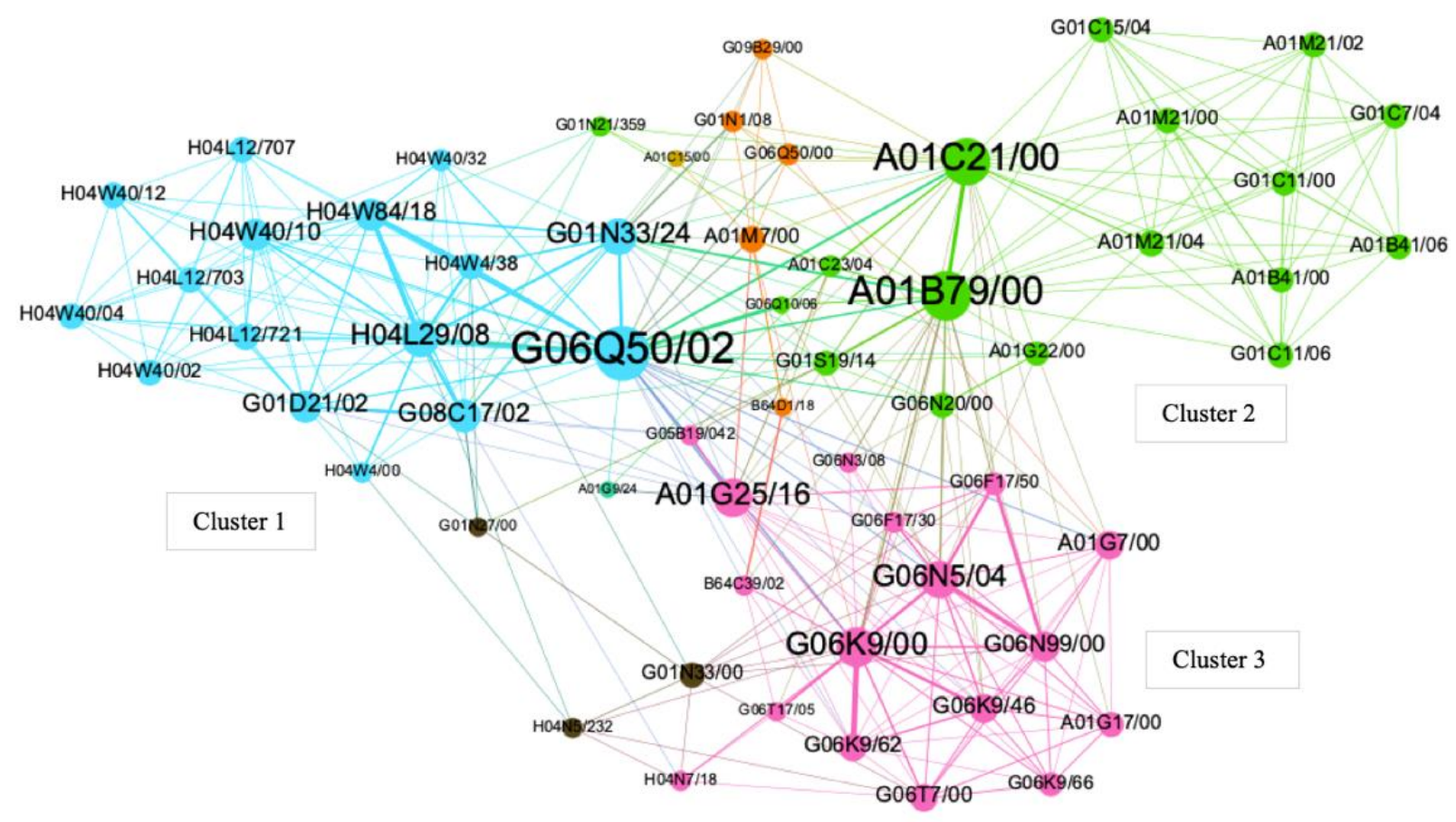

Fonte: Dados da pesquisa.

Observa-se que as tecnologias que tiveram maior relação com outros setores foram: sistemas voltados especificamente para o setor da agricultura (G06Q 50/02), métodos para preparação do solo com máquinas especiais (A01B 79/00), métodos de fertilização (A01C 21/00), métodos para leitura e identificação de padrões (G06K 9/00) e métodos ou dispositivos de inferência (G06N 5/04). Os pares das tecnologias mais encontradas em uma mesma patente foram os procedimentos de controle de transmissão de dados (H04L 29/08) e os sistemas voltados para a agricultura (G06Q50/02). A análise de rede também permitiu identificar três grandes clusters de colaboração entre campos tecnológicos: técnica de comunicação elétrica (cluster 1), agricultura (cluster 2) e processamento de dados (cluster 3).

Este estudo também realizou a análise das relações colaborativas entre os depositantes identificados na pesquisa. A cooperação entre os requerentes é medida a partir da cotitularidade dos pedidos de patentes associadas à Agricultura de Precisão (Figura 12). A análise de rede permite a identificação direta da conexão desses atores em seu ambiente tecnológico, ou seja, podem ser reconhecidos como hubs em uma rede de cooperação ou como pontes entre diferentes sub-redes (Sternitzke et al., 2008).

Para melhorar a visibilidade da rede, foram considerados apenas os requerentes com pelo menos um pedido de patente com cotitularidade. Nota-se que foram identificados apenas dois requerentes como pontes entre sub-redes: o Instituto Malaio de Sistemas Microeletrônicos (Mimos Berhad) com duas patentes no campo de dispositivos elétricos publicadas em 2010 e 2011 (uma em cada sub-rede), nas quais os demais cotitulares são os próprios inventores; e o requerente e inventor russo Voronkov Nikolaevich, com duas patentes divididas em duas sub-redes. As patentes abordam sistemas de informações para engenharia agrícola de precisão. Vale destacar que os principais requerentes, apresentados na Figura 5, não realizaram depósitos em cooperação e aqueles que o fazem pertencem a grupos isolados, conforme apresentado na Figura 12. 
Figura 12 - Rede de cooperação de requerentes das patentes da Agricultura de Precisão.

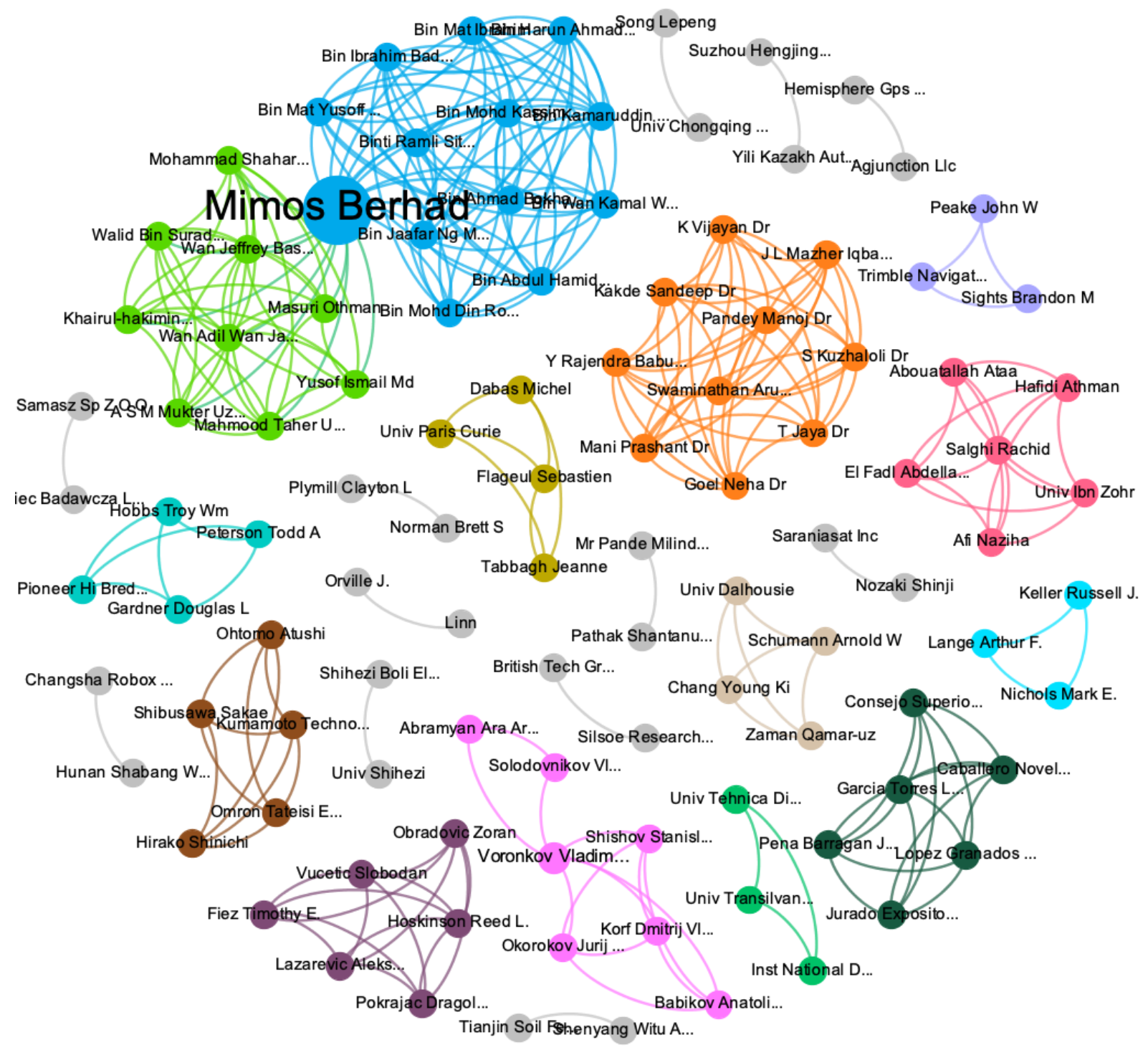

Fonte: Dados da pesquisa.

O comportamento de cooperação dos inventores de patentes associadas à Agricultura de Precisão também foi investigado. Para medir a cooperação entre inventores considera-se a co-invenção de famílias de patentes. Para melhorar a visibilidade da rede, foram considerados apenas os inventores com pelo menos sete invenções em comum (Figura 13).

O tamanho do nó define o nível de centralidade de intermediação do inventor dentro da rede, ou seja, inventores que atuam como interfaces ou links entre diferentes grupos de inventores ou departamentos. Isso implica dizer os indivíduos que estão posicionados como corretores de informações entre grupos com diferentes origens de informações se beneficiam de fluxos de dados, o que influencia positivamente sua produção quantitativa e qualitativa (Sternitzke et al., 2008).

Os inventores com maior centralidade de intermediação nas invenções da Agricultura de Precisão foram: Zhu Dehai, Wang Maohua, Feng Wei, Zhu Yan e Ni Jun. Esses dois últimos estão entre os quatro maiores inventores do setor. Eles também apresentam o maior nível de cooperação entre si, totalizando sete patentes. Por outro lado, os inventores com maior número de invenções não possuem patentes com muitos co-inventores, uma vez que procuram se manter em grupos menores. 
No geral, as sub-redes analisadas se dedicaram à invenção de apenas uma patente. Algumas sub-redes possuem mais de 10 coinventores, sendo a maior delas com 14 membros.

Figura 13 - Rede de cooperação entre os inventores das patentes da Agricultura de Precisão.

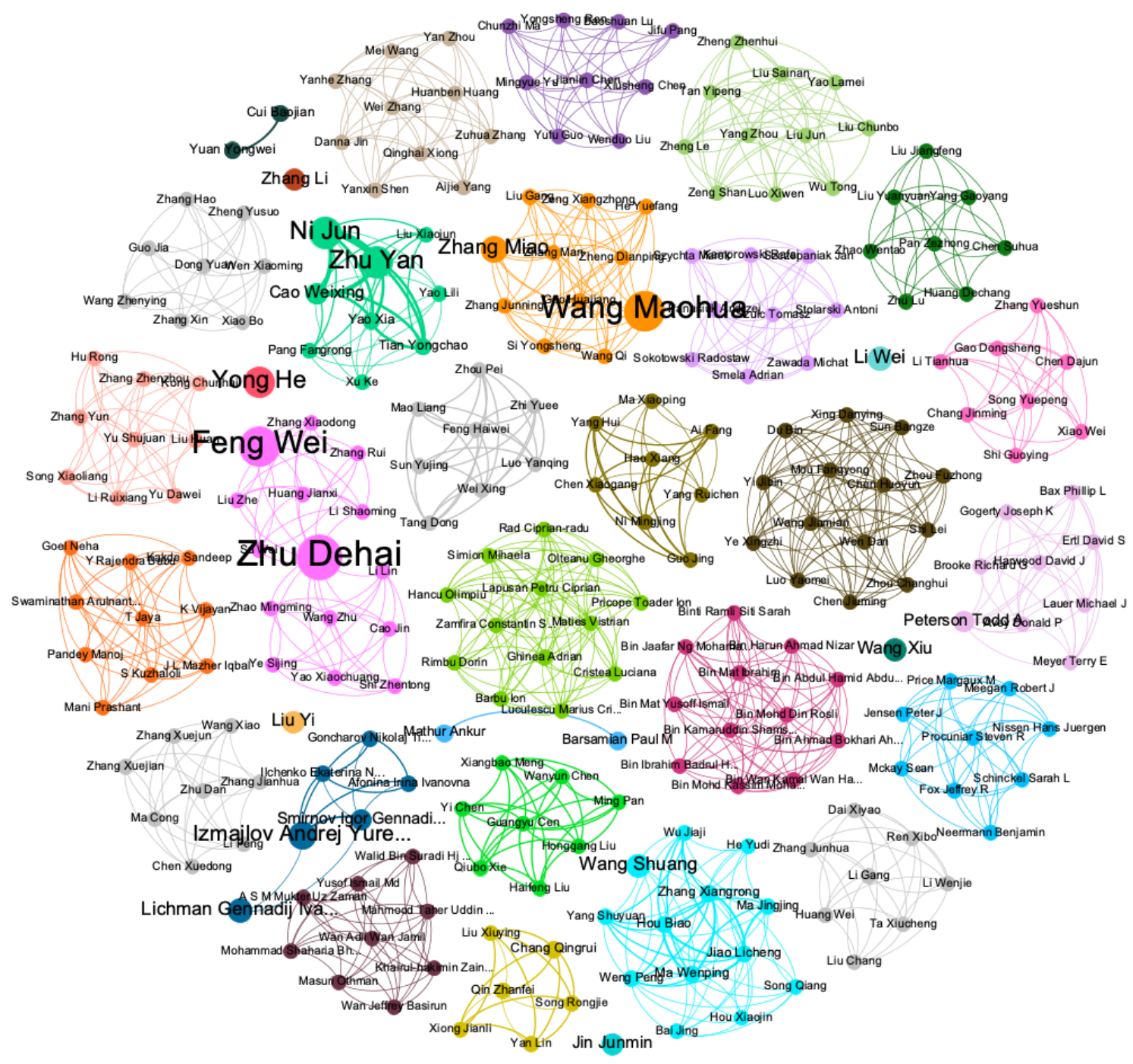

Fonte: Dados da pesquisa.

\section{Conclusões e Considerações Finais}

O Este estudo adotou diversas técnicas de análise bibliométrica, de mineração de texto e de redes sociais para identificar o estágio atual do desenvolvimento tecnológico no campo da Agricultura de Precisão (AP), mapeando os principais depositantes e inventores, suas tecnologias e estruturas sociais e os países nos quais elas estão sendo desenvolvidas e protegidas, a partir da análise de informações das patentes. Também forneceu um fluxo metodológico apoiado por ferramentas de software de código aberto e gratuito para coleta, tratamento e visualização de dados a serem utilizados em diferentes tipos de análise.

O monitoramento das tecnologias associadas à Agricultura de Precisão permitiu a elaboração de indicadores quantitativos e qualitativos de patentometria em resposta às questões da pesquisa apresentadas na introdução deste estudo. 
(Questão 1) A publicação dos depósitos das tecnologias que abordam a AP iniciou em 1995, com uma taxa anual de crescimento de $16,5 \%$ até 2020. No entanto, seu crescimento regular se deu a partir de 2013, tendo acumulado 312 famílias de patentes, das quais cerca de $90 \%$ foram publicadas na última década. Observa-se uma tendência de crescimento para os próximos anos, podendo chegar ao montante de 500 depósitos em 2024.

(Questão 2) Os 312 produtos tecnológicos analisados foram depositados por 303 titulares distintos, desenvolvidos por 968 inventores e protegidos em 23 países. Cada tecnologia possui em média 1,3 titulares e 3,8 inventores, porém cerca de 85\% dos titulares possuem apenas um depósito. Entre os principais depositantes encontram-se empresas, universidades e pessoas físicas, sendo o maior deles a empresa americana Iteris Inc. Alguns dos principais titulares compartilham dos principais inventores, como John J. Mewes e Dustin M. Salentiny, os quais fazem parte do grupo de 0,2\% dos inventores que desenvolveram mais de 10 patentes, enquanto 86\% participaram de apenas uma invenção. Quanto à jurisdição dos depósitos, o primeiro foi realizado nos Estados Unidos, que atualmente ocupa a segunda posição no ranking das patentes depositadas, perdendo apenas para a China e à frente da Rússia. Juntos esses países somam 86\% dos depósitos realizados e publicados.

(Questão 3) Os 312 depósitos relativos à Agricultura de Precisão se dividem em 7 seções, 29 classes e 75 subclasses da Classificação Internacional de Patentes (IPC). Os setores tecnológicos estão relacionados principalmente ao plantio, processamento de dados e análise de propriedades do solo, mas também foram identificadas tecnologias associadas a redes wireless, equipamentos para aeronaves, sistemas de engrenagens e aparelhos de pulverização. De forma complementar, a mineração de dados não estruturados e o uso de algoritmos de clusterização permitiram extrair padrões e tendências temáticas das patentes, os quais observa-se o uso de sensoriamento remoto hiperespectral, processamento de imagens, fertilização precisa, veículo aéreo não tripulado, entre outros.

(Questão 4) As patentes mais relevantes da Agricultura de Precisão constituem a sua base tecnológica e podem ser identificadas como as patentes altamente citadas por outros depósitos. Até a data deste estudo, os três principais documentos de patentes foram citados mais de 130 vezes, sendo o primeiro depósito publicado, o mais citado (375 citações). Os setores tecnológicos das patentes altamente citadas abordam sistemas para processamento de imagens espectrais da vegetação, sistemas para posicionamento espacial preciso e sistemas de coleta de amostras georreferenciadas do solo.

(Questão 5) A estrutura conceitual da Agricultura de Precisão foi demonstrada por meio da rede de coocorrência das classificações de patentes, sobretudo dos subgrupos IPC. A análise da rede apontou três grandes clusters de cooperação entre os campos tecnológicos, formando uma tríade: Agricultura, Processamento de dados e Comunicação. Destacam-se como tecnologias que mais se relacionam na Agricultura de Precisão: sistemas agrícolas, preparação do solo, fertilização, identificação de padrões e métodos de inferência. Em relação às estruturas sociais, verificou-se que praticamente não há intermediação de titulares entre os grupos de desenvolvimento das tecnologias e os principais requerentes das patentes não realizam depósitos em cooperação com os demais. Por outro lado, os principais inventores participam de forma mais cooperativa, inclusive sendo pontes entre diferentes grupos de inventores.

Por fim, conclui-se que o monitoramento tecnológico da Agricultura de Precisão a partir da análise de patentes permite a compreensão do estado de desenvolvimento da tecnologia em questão, considerando diferentes aspectos das atividades de patenteamento. As conexões identificadas entre os provedores das tecnologias podem ser usadas para análise de concorrentes ou para identificar parceiros para projetos de desenvolvimento conjuntos. Portanto, o resultado deste trabalho pode ajudar tanto pesquisadores quanto profissionais e empresas do setor.

Este estudo não está isento de limitações. Ainda que a maioria dos dados disponibilizados na base de dados sejam confiáveis, alguns registros possuem campos vazios, incompletos ou inconsistentes que impossibilitam a análise de dados das reivindicações e das descrições das patentes. As ferramentas de softwares livres e gratuitas utilizadas agilizam o processo de coleta, tratamento e análise dos dados patentários, porém demandam certa curva de aprendizado para melhor aproveitamento 
dos recursos e profundidade da análise, como por exemplo o desenvolvimento de redes de cooperação entre titulares e inventores das patentes, ou ainda, a criação de redes de cocitação.

Em contrapartida, as limitações listadas aqui oferecem oportunidades para novos estudos, visando expandir os resultados desta pesquisa ao agregar novas bases de dados e combinar o uso de ferramentas complementares para contornar as limitações das ferramentas, otimizando ainda mais o processo de monitoramento das tecnologias da Agricultura de Precisão e de outras áreas.

\section{Referências}

Abbas, A., Zhang, L., \& Khan, S. U. (2014). A literature review on the state-of-the-art in patent analysis. World Patent Information, 37, 3-13. https://doi.org/10.1016/j.wpi.2013.12.006

Adamchuk, V. ., Hummel, J. ., Morgan, M. ., \& Upadhyaya, S. . (2004). On-the-go soil sensors for precision agriculture. Computers and Electronics in Agriculture, 44(1), 71-91. https://doi.org/10.1016/j.compag.2004.03.002

Bastian, M., Heymann, S., \& Jacomy, M. (2009). Gephi: an open source software for exploring and manipulating networks. Proceedings of the International AAAI Conference on Web and Social Media, 3(1), 361-362. https://ojs.aaai.org/index.php/ICWSM/article/view/13937

Batagelj, V., \& Mrvar, A. (1998). Pajek-program for large network analysis. Connections, 21, 47-57. http://vlado.fmf.uni-lj.si/pub /Networks/doc/pajek.pdf

Brereton, P., Kitchenham, B. A., Budgen, D., Turner, M., \& Khalil, M. (2007). Lessons from applying the systematic literature review process within the software engineering domain. Journal of Systems and Software, 80(4), 571-583. https://doi.org/10.1016/j.jss.2006.07.009

Carrot2. (2021). Carrot2 clustering engine. https://carrot2.org/

Chang, P.-L., Wu, C.-C., \& Leu, H.-J. (2010). Using patent analyses to monitor the technological trends in an emerging field of technology: a case of carbon nanotube field emission display. Scientometrics, 82(1), 5-19. https://doi.org/10.1007/s11192-009-0033-y

Cisternas, I., Velásquez, I., Caro, A., \& Rodríguez, A. (2020). Systematic literature review of implementations of precision agriculture. Computers and Electronics in Agriculture, 176(July), 105626. https://doi.org/10.1016/j.compag.2020.105626

Demsar, J., Curk, T., Erjavec, A., Gorup, C., Hocevar, T., Milutinovic, M., Mozina, M., Polajnar, M., Toplak, M., Staric, A., Stajdohar, M., Umek, L., Zagar, L., Zbontar, J., Zitnik, M., \& Zupan, B. (2013). Orange: Data Mining Toolbox in Python. Journal of Machine Learning Research, 14(Aug), 2349-2353. http://jmlr.org/papers/v14/demsar13a.html

Ham, K. (2013). OpenRefine (version 2.5). http://openrefine.org. Free, open-source tool for cleaning and transforming data. Journal of the Medical Library Association : JMLA, 101(3), 233-234. https://doi.org/10.3163/1536-5050.101.3.020

Kent Shannon, D., Clay, D. E., \& Sudduth, K. A. (2018). An Introduction to Precision Agriculture (p. 1-12). https://doi.org/10.2134/precisionagbasics.2016.0084

Lotka, A. J. (1926). The freq distrib of scientific productivity. Journal of the Washington Academy of Sciences, 16(12), 317-323.

Martínez, C. (2011). Patent families: When do different definitions really matter? Scientometrics, 86(1), 39-63. https://doi.org/10.1007/s11192-010-0251-3

Masiakowski, P., \& Wang, S. (2013). Integration of software tools in patent analysis. World Patent Information, 35(2), 97-104. https://doi.org/10.1016/j.wpi.2012.12.010

Osiński, S., Stefanowski, J., \& Weiss, D. (2004). Lingo: Search Results Clustering Algorithm Based on Singular Value Decomposition. In Intelligent Information Processing and Web Mining (Vol. 20, Número 3, p. 359-368). Springer Berlin Heidelberg. https://doi.org/10.1007/978-3-540-39985-8_37

Pereira, J. M. (2016). Manual de Metodologia da Pesquisa Científica (4º ed). Atlas.

Precision Agriculture in the 21st Century. (1997). Precision Agriculture in the 21st Century. National Academies Press. https://doi.org/10.17226/5491

Silva, W. de V. R. da, Adelino, M. A., Silva, M. V. da, Silva, F. C. da, \& Silva-Mann, R. (2020). Análise da produção científica e tecnológica acerca da Ciência Forense Digital. Research, Society and Development, 9(11), e45391110224. https://doi.org/10.33448/rsd-v9i11.10224

Silva, W. de V. R. da, \& Silva-Mann, R. (2020). Agricultura de Precisão no Brasil: conjuntura atual, desafios e perspectivas. Research, Society and Development, 9(11), e1979119603. https://doi.org/10.33448/rsd-v9i11.9603

Silva, W. de V. R. da, \& Silva-Mann, R. (2021). Precision Agriculture under a bibliometric view. International Journal for Innovation Education and Research, 9(11), 422-442. https://doi.org/10.31686/ijier.vol9.iss11.3533

Sternitzke, C., Bartkowski, A., \& Schramm, R. (2008). Visualizing patent statistics by means of social network analysis tools. World Patent Information, 30(2), 115-131. https://doi.org/10.1016/j.wpi.2007.08.003

Tableau. (2021). Tableau Public. SAGE Publications, Ltd. https://doi.org/10.4135/9781529776669

The Lens. (2021). About The Lens. https://about.lens.org/ 
Research, Society and Development, v. 11, n. 3, e42611326852, 2022

(CC BY 4.0) | ISSN 2525-3409 | DOI: http://dx.doi.org/10.33448/rsd-v11i3.26852

WIPO. (2016). The WIPO Manual on Open Source Patent Analytics. https://wipo-analytics.github.io/

Yang, Z. K., Lin, D. M., \& Xu, M. Z. (2014). The Re-applicability Explore of Lotka's Law in Patent Documents. Collnet Journal of Scientometrics and Information Management, 8(1), 183-191. https://doi.org/10.1080/09737766.2014.916875 